\section{A personal therapeutic journey}

\author{
Cicely Saunders
}

I began training as a ward nurse in 1941 at St Thomas's Hospital. We had a limited pharmacopoeia, which gradually included sulphonamides but no other antibiotics, and few of the other drugs that we now take for granted. There were no diuretics, antihypertensive drugs, antiemetics, or any psychotropic drugs beyond barbiturates and chloral. Linctus, mist expectorans, or mist potassium iodids, and the evil tasting potassium citrate were regularly prescribed, and much of what we offered would today be dismissed as "custodial care." We boiled up our "porringers" for lotions, folded our dressings for autoclaving, and reused our needles after a period in spirit. Operation days were a nightmare of vomiting patients.

Young patients dying of tuberculosis and septicaemia from war wounds begged us to save them somehow, but we had little to offer except devoted nursing. Osteomyelitis led to amputation and gastric ulcers to a milk diet. Penicillin appeared after D Day, when soldiers arrived saying that they could not face another blunt needle. We had morphine by injection but used it sparingly.

We worked a duty of 12 nights on, two nights off for three months, with split duties by day, and we had one day off a week from $5 \mathrm{pm}$ the previous day. I was tired but deeply happy and satisfied. I have never lost touch with my set: the remaining members still meet regularly.

Invalided out with back trouble, I returned to Oxford in 1944, completed a war degree, had a laminectomy, and became a lady almoner (now known as a medical social worker) back at St Thomas's.

\section{Brompton cocktails}

In March 1948 I began working as a volunteer nurse once or twice a week in one of the early homes for "terminal care." St Luke's Hospital had 48 beds for patients with advanced cancer. Here I met the regular administration of a modified "Brompton cocktail" every four hours. The St Luke's version omitted the cannabis and, I think, the cocaine. They adjusted the morphine dose to the patient's need; if more than $60 \mathrm{mg}$ was required the route was changed to injection. Hyoscine was used with morphine for terminal restlessness.

From 1951 to 1957 I was a medical student, yet again at St Thomas's. During that time there was a revolution in the drugs available for control of symptoms. The first phenothiazines, the antidepressants, the benzodiazepines, the synthetic steroids, and the non-steroidal anti-inflammatory drugs had all come into use by the time I arrived at St Joseph's Hospice in October 1958. A clinical research fellowship from the Department of Pharmacology at St Mary's Hospital Medical School under Professor Harold Stewart enabled me to begin work there to investigate terminal pain and its relief.

St Joseph's Irish Sisters of Charity had welcomed the local chest physician with the new antituberculosis drugs in the early 1950 s and were ready for further innovations. The two visiting general practitioners were pleased to have help. They had already begun using chlorpromazine but they were not giving morphine orally or regularly, relying on injections as required and pethidine by mouth. Oral morphine together with alcohol and cocaine was introduced with cyclizine as the main antiemetic. The doses were nearly all as low as I had seen in St Luke's. The therapeutic advances and having the time to sit and listen to a patient's story, transformed the wards.

Gradually, we began to tackle the other symptoms. I tried to set up a trial of nepenthe (an oral opioid) with or without aspirin but found the almost solo clinical care of patients in 45 beds made completion impossible. Instead, I was able to report to the Royal Society of Medicine in November 1962 on analysed records of 900 patients showing that "tolerance and addiction are not problems to us, even with those who stay longest." ${ }^{1}$

\section{Greater confidence}

We had by that time begun to use diamorphine. There were no controlled trials of this drug to be found, only some clinical reports that it had few side effects. We used it for $\mathbf{4 2}$ of our first 500 patients, in women with severe nausea and in a few patients with intolerable feelings of suffocation. By that time we believed that this was the drug of choice, but I realised two things. Firstly, we were getting better and more confident in all that we were doing, secondly, that your own enthusiasms must be tested. The later work at St Christopher's Hospice by Twycross showed that there was no clinically observable difference between morphine and diamorphine given orally in our setting and with adjuvant treatment. ${ }^{2}$

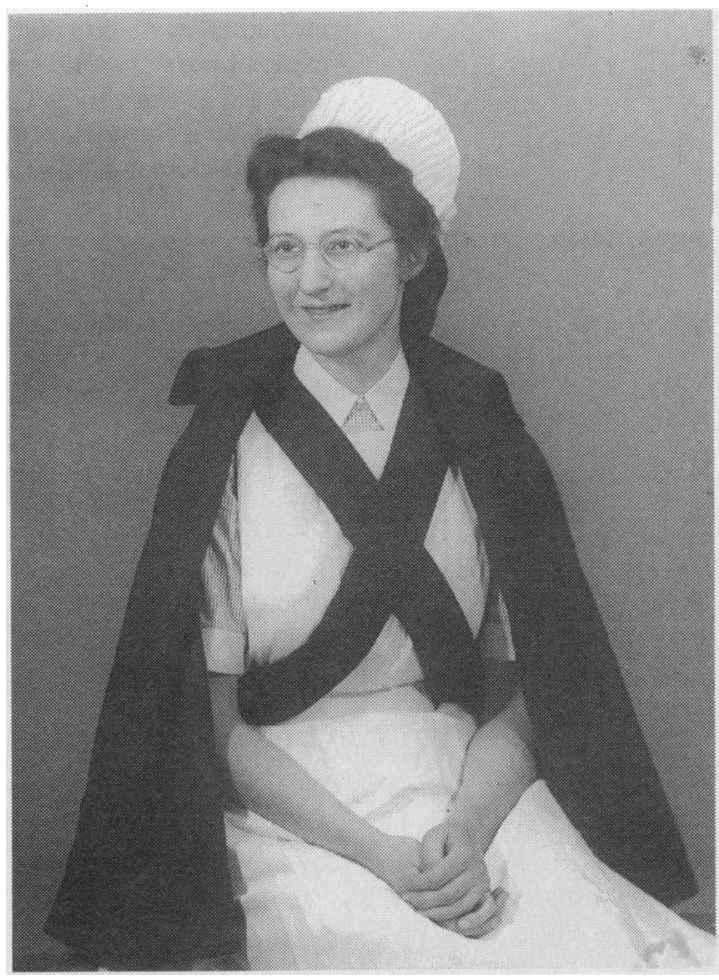

Cicely Saunders at the end of her first year as a nurse 


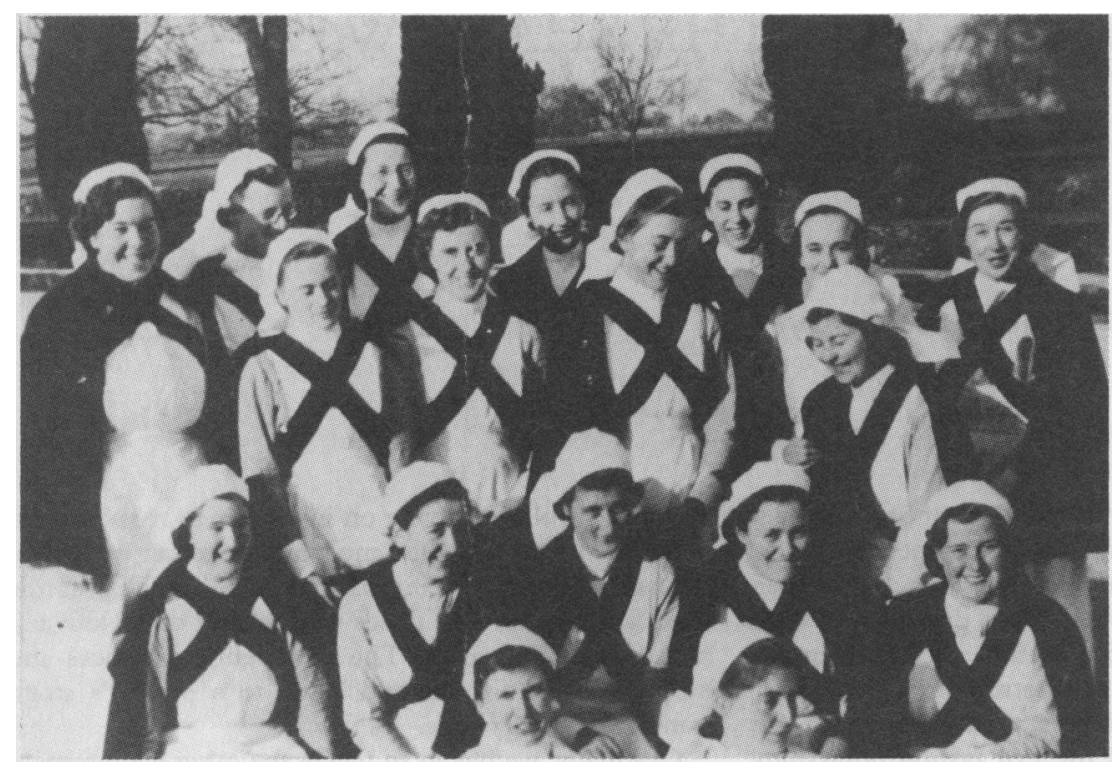

The set in 1940. Cicely Saunders is in top row, third from left

During the seven years at St Joseph's between 1958 and 1965 we increased our pharmacopoeia, our patients' activities, their discharges, and referrals back for radiotherapy. Gautier Smith came occasionally to perform nerve blocks. I wrote and lectured widely and produced a handout of the drugs in common use at St Joseph's and at St Christopher's Hospice, which opened in 1967. The handout has been updated, enlarged, and reproduced widely. It has, of course, been joined by books and pamphlets from Twycross and others. We now have the Oxford Textbook of Palliative Medicine. The fundamentals of therapeutics I believe remain as I wrote in 1963:

We believe that there are a few cardinal rules in the treatment of intractable pain at this stage. First, we have to make as careful an assessment as possible of the symptoms that trouble the patient. This is not in order to make a diagnosis and give specific treatment, because that has already been done, but in order to treat pain and all the other things that can add up to a general state of misery as a disease in itself.

It soon became clear that each death was as individual as the life that preceded it and that the whole experience of that life was reflected in a patient's dying. This led to the concept of "total pain," which was presented as a complex of physical, emotional, social, and spiritual elements. The whole experience for a patient

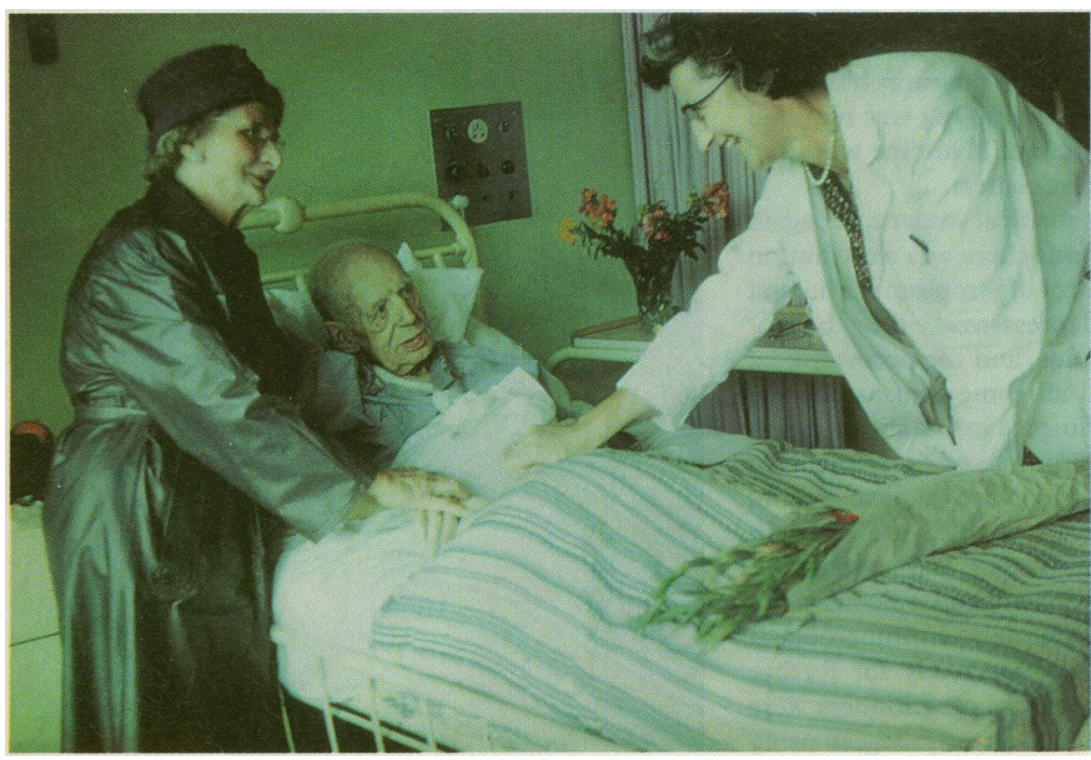

St Joseph's Hospice, 1960 includes anxiety, depression, and fear; concern for the family who will become bereaved; and often a need to find some meaning in the situation, some deeper reality in which to trust. This became the major emphasis of much lecturing and writing on subjects such as the nature and management of terminal pain and the family as the unit of care. ${ }^{34}$

\section{Importance of active total care}

It was recognised that support was needed both before and after a patient's death, particularly in home care, when the family are the central carers. The World Health Organisation has published the following definition, "Palliative care is the active total care of patients whose disease is not responsive to curative treatment Control of pain, of other symptoms and of psychological, social and spiritual problems is paramount. The goal of palliative care is achievement of the best possible quality of life for patients and their families." 5

The basic and clinical researchers, together with many clinicians-doctors, nurses, and many in auxiliary services-have enlarged our detailed knowledge of physical pain since that was written. The emphasis on regular giving has been accepted widely and also features as an essential element in relieving the pain of cancer. It is one of the cardinal principles of the WHO booklet Cancer Pain Relief, available in many languages and now in a second edition ${ }^{6}$. Over 33 years later, these basic principles have not changed, although symptomatic treatment is far more complex and specialists in palliative care have to keep abreast of developments in all relevant disciplines.

Many therapeutic discoveries of recent years have been relevant to palliative care. For example, the pharmacological management of terminal bowel obstruction has been improved with the use of octreotide. Hypercalcaemia is now identified and treated with bisphosphonates. In the drive to question received wisdom, investigations continue into the best and appropriate ways of treating dyspnoea and the problems arising from dehydration (not always symptomatic). Neuropathic pain is better managed but still needs further work. Looking ahead, I sometimes wonder that if we are not careful we may see a postantibiotic era. Whatever happens, it will still matter that we go on listening and that we continue our questioning. Above all, my experience emphasises that the practice of medicine includes more than specific treatments.

\section{We were the hosts}

The advances in pharmacology and the new technologies are not the whole story. At our preliminary training school we were taught that we were host to our patients and their visiting families. It was also taken for granted that we would join in ward prayers morning and evening and carry out "last offices" with reverence and respect. Life has changed greatly in over 55 years, but people's needs, though expressed differently, remain beyond the strictly physical. Palliative care physicians are not to be merely "symptomologists," as Kearney has expressed it.

Now that palliative care is spreading worldwide it has still, as in the WHO definition, kept a concern for the spiritual needs of its patients and their families. The whole approach has been based on the understanding that a person is an indivisible entity, a physical and a spiritual being. "The only proper response to a person is respect; a way of seeing and listening to each one in the whole context of their culture and relationships, thereby giving each his or her intrinsic value " (M Mayne, personal communication). The search for meaning, for something in which to trust, may be expressed in many ways, direct and indirect, in metaphor or silence, in ges- 
This picture of Cicely Saunders will feature in an exhibition of photographs of doctors of the 20 th century being organised by the $B M \mathcal{F}$ and held at the National Portrait Gallery in London from 10 March 1997 (p 1633). There will also be a book.

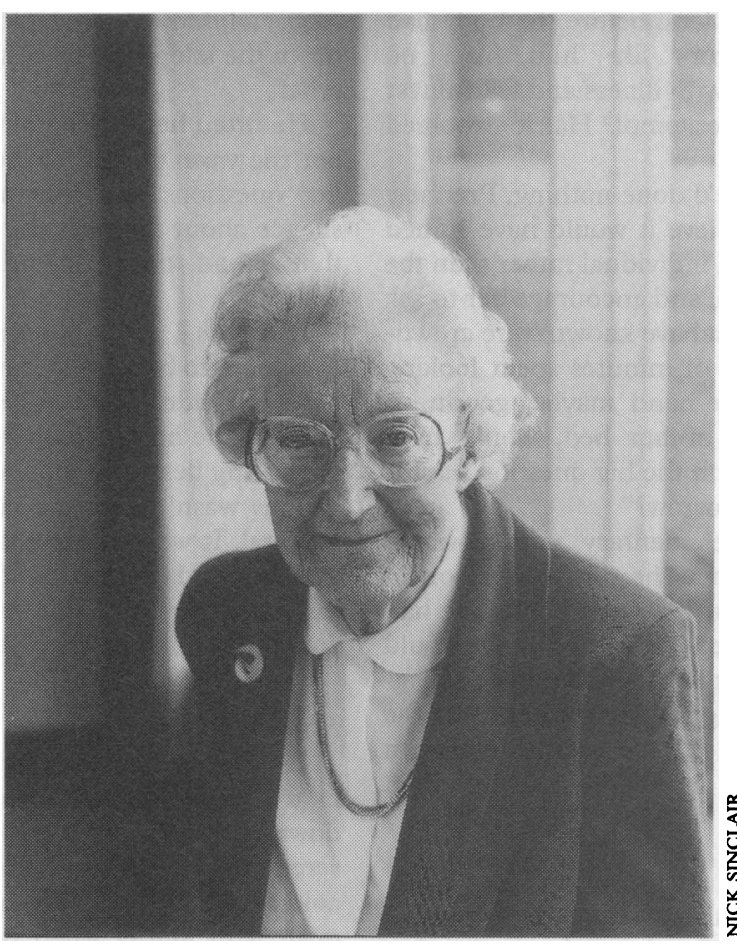

Dame Cicely Saunders today

ture or symbol or, perhaps most of all, in art and the unexpected potential for creativity at the end of life.

Those who work in palliative care may have to realise that they, too, are being challenged to face this dimension for themselves. Many, both helper and patient, live in a secularised society and have no religious language. Some will, of course, still be in touch with their religious roots and find a familiar practice, liturgy, or sacrament to help their need. Others, however, will not. For them insensitive suggestions by well meaning practitioners will be unwelcome. How- ever, if we can come not only in our professional capacity but in our common, vulnerable humanity there may be no need of words on our part, only of concerned listening. For those who do not wish to share their deepest needs, the way care is given can reach the most hidden places. Feelings of fear and guilt may seem inconsolable, but many of us have sensed that an inner journey has taken place and that a person nearing the end of life has found peace. Important relationships may be developed or reconciled at this time and a new sense of self worth develop. A recent study shows how this may happen in late modern social conditions. ${ }^{8}$

My personal therapeutic journey has witnessed an extraordinary growth in drug treatments for pain and other symptoms. The challenge of educating others on their use remains. However, there has always been a human as well as a professional basis that is fundamental to the work that we do. Everyone meeting these patients and their families is challenged to have some awareness of this dimension. Professionals' own search for meaning can create a climate, as we tried often helplessly to do all those years ago, in which patients and families can reach out in trust towards what they see as true and find courage and acceptance of what is happening to them.

Research at St Joseph's and St Christopher's Hospices was supported by the Sir Halley Stewart Trust and the Department of Health and Social Security.

1 Saunders $C$. The treatment of intractable pain in terminal cancer. Proceedings of the Royal Society of Medicine 1963;56:195-7.

2 Twycross $\mathbf{R}$. Choice of strong analgesic in terminal cancer care: morphine or diamorphine? Pain 1977;3:93-104.

3 Saunders C. The challenge of terminal care. In: Symington T, Carter RL eds. Scientific foundations of oncology. London: Heinemann Medical Medical Books Ltd, 1976:673-9.

4 Saunders. C. The care of the dying patient and his family. Contact 1972;38:12-8.

5 World Health Organisation. Cancer pain relief. Geneva: WHO, 1996.

6 World Health Organisation Expert Committee. Report. Cancer pain relief and

palliative care. Geneva: WHO, 1990:11.
7 Kearney M. Palliative medicine-just another specialty? Palliative Kearney M. Palliative
Medicine 1992;6:39-46.

8 Seale C. Heroic death. Sociology 1995;29:597-613.

\section{Oh, for a little humanity}

\section{Sally Magnusson}

Not many laughs this last fortnight. I went to visit a close friend in a hospital near London who had recently had a breast lump and her lymph glands removed. I found her curled like a fetus on her bed in one of those grim wards that seem positively designed to make you feel ill.

I was shocked by how utterly drained and beaten she looked. She had been home since the operation and had sounded quite perky on the telephone. Yet after being in this hospital for only a couple of days she looked finished.

Physically, it transpired, she was feeling not too bad; emotionally she was wrecked. Two days before, still weak from the operation, she had been invited to turn up at $1000 \mathrm{am}$ to learn the results of a scan. She waited all day. At $600 \mathrm{pm}$ she was told that she had cancer of the liver and four small brain tumours. She seemed to have no idea what the treatment would be, whether it was worth having, what her options were, where she would have it, what the effects might be. To just about all of the hundred and one questions I asked her, she said: "I don't know."

"Haven't you asked the doctor?" I kept saying. Oh, she had tried. But he was so dry, so distant, always in such a hurry. It wasn't that he was rude, exactly, just that he never looked her in the eye, never seemed to speak directly to her, just barked questions at the nurse over her head, and grunted in reply.

"I kept trying to focus on the right question, but the next minute he was gone. In and out like a whirlwind. It happens every time I see him. I get so confused. He flusters me. Nothing comes out right. I think he's taken one look at that scan and consigned me to the scrap heap. Three people have died in this ward since I got here. All I can think about is whether I'm going to wake up tomorrow.

\section{"Am I going to wake up tomorrow?"}

"Am I going to wake up tomorrow, Sally? Will I be here in a few weeks time? Can you look me in the eye and tell me that?"

I looked her in the eye and said, very slowly and wishing I knew more about the liver: "I am absolutely certain that you're going to be here in a few weeks time."

She relaxed, even smiled a bit, and began to talk about other things. I sat there wrestling with my rage.

Who was this man who called himself a healer yet could so effortlessly turn an illness into a trauma and so 